Short communication

\title{
Phenolic profiles, antioxidant activity and in vitro antiviral properties of apple pomace
}

\author{
Belén Suárez ${ }^{\mathrm{a}}$, Ángel L. Álvarez ${ }^{\mathrm{b}}$, Yolanda Diñeiro García ${ }^{\mathrm{a}}$, Gloria del Barrio ${ }^{\mathrm{b}}$, \\ Anna Picinelli Lobo ${ }^{\mathrm{a}, *}$, Francisco Parra ${ }^{\mathrm{c}}$ \\ a Área de Tecnología de los Alimentos, Servicio Regional de Investigación y Desarrollo Agroalimentario (SERIDA), 33300 Villaviciosa, Asturias, Spain \\ bepartamento de Microbiología y Virología, Facultad de Biología, Universidad de La Habana, 10400 La Habana, Cuba \\ ${ }^{\mathrm{c}}$ Departamento de Bioquímica y Biología Molecular, Universidad de Oviedo, 33006 Oviedo, Asturias, Spain
}

\section{A R T I C L E I N F O}

\section{Article history:}

Received 11 November 2008

Received in revised form 30 March 2009

Accepted 22 September 2009

\section{Keywords:}

Apple pomace

Antioxidant

Antiviral

Herpes

\begin{abstract}
A B S T R A C T
Methanolic and acetonic extracts of apple pomace were evaluated for phenolic profiles, antioxidant properties and antiviral effect against herpes simplex virus type 1 (HSV-1) and 2 (HSV-2). Acetone extraction yielded the higher amounts of phenolic compounds. The extraction method influenced the phenolic composition although antioxidant activity correlated weakly with phenols concentration. Among the polyphenols analysed, quercetin glycosides were the most important family, followed by dihydrochalcones. Apple pomace extracts were able to inhibit both HSV-1 and HSV-2 replication in Vero cells by more than $50 \%$, at non-cytotoxic concentrations. Selectivity indexes (SI) ranged from 9.5 to 12.2 .
\end{abstract}

(c) 2009 Elsevier Ltd. All rights reserved.

\section{Introduction}

Apple pomace is a by-product of the apple cider processing industry and represents about $20-35 \%$ of the original fruits. Disposal of apple pomace may present an added cost to beverage industry: on the one hand, its use as fertilizer (compost) without any pre-treatment or in landfills may not continue to be acceptable for evident environmental concerns. On the other hand, this product is a poor animal feed because of its low protein content and its seasonally-restricted availability. For these reasons, exploration of potential alternative uses for this apple waste is needed.

According to epidemiologic studies, diets rich in fruits and vegetables have been associated with reduced risk of developing chronic diseases, such as cardiovascular disease, cancer, diabetes and Alzheimer's disease (Block, Patterson, \& Subar, 1992; Hertog, Feskens, Hollman, Katan, \& Kromhout, 1993). Phytochemical compounds, particularly polyphenols, have been suggested to be responsible for the health benefits in most of these foods. Apple extracts have been shown to have potent antioxidant activity and antiproliferative activity against human cancer cells (Boyer, Brown, \& Liu, 2004; Leontowicz et al., 2002).

Previous studies indicating its phenolic content and high antioxidant activity aim to regard apple pomace as a valuable source

\footnotetext{
* Corresponding author. Tel.: +34 985890066; fax: +34 985891854

E-mail address: apicinelli@serida.org (A. Picinelli Lobo).
}

of natural antioxidants and bioactive compounds (Foo \& Lu, 1999; Lu \& Foo, 1997, 2000; Ćetković et al., 2008).

Herpes simplex virus type 1 (HSV-1) and 2 (HSV-2) (family Herpesviridae) are responsible for a broad spectrum of clinical symptoms in humans, varying from mild skin vesicular lesions to severe manifestations such as encephalitis, conjunctivitis, eczema, pneumonia and hepatitis (Whitley, Kimberlin, \& Roizman, 1998). Flavonoid-rich extracts and fractions from fruits have been found to inhibit acyclovir-resistant strains of these viruses (Cos, Berghe, Bruyne, \& Vlietinck, 2003; Goncalves et al., 2001). However, scarce information is available on antiviral activity of apple pomace. In this work, we present the phenolic profiles and antioxidant abilities of two (methanolic and acetonic) extracts from apple pomace, and preliminary data on their inhibitory activity against HSV-1 and HSV-2 in vitro propagation.

\section{Materials and methods}

\subsection{Materials}

\subsubsection{Apple pomace}

All apple pomace used throughout this work was generated from a mixture of cider apples from El Gaitero S.A. cellar (Villaviciosa, Asturias, Spain). The fresh apple pomace was oven-dried in convection at $60^{\circ} \mathrm{C}$ until it reached a constant weight. The dried pomace was then homogenised, ground to $0.5 \mathrm{~mm}$ particles with a Cyclotek 1093 (Foss-Tekator) and vacuum stored. 


\subsubsection{Viruses and cells}

HSV-1 and HSV-2 clinical isolates were kindly provided by Dr. María Oña (Virology Department, Asturias Central Hospital). Both herpes viruses were propagated in green monkey kidney (Vero) cells (ECACC No. 84113001) and titrated by microscopical visualisation of cytopathic effect (CPE), using the endpoint dilution method described by Reed and Muench (1938). Vero cells were grown in Dulbecco modified Eagle's essential minimal medium (DMEM) supplied with $10 \%$ foetal bovine serum. Cells were maintained in DMEM with serum concentration reduced to $2 \%$.

\subsubsection{Reagents}

Folin-Ciocalteu reagent was supplied by Merck (Darmstadt, Germany). 2,2'-Diphenyl- $\beta$-picrylhydrazyl (DPPH), 2,4,6-tris-(2pyridyl)-s-triazine (TPTZ), ascorbic acid, ferric chloride and sodium acetate were obtained from Sigma-Aldrich (St. Louis, MO, USA). Polyphenol standards were supplied as follows: gallic acid, protocatechuic acid, (+)-catechin, (-)-epicatechin, phloridzin, hydroxycinnamic acids ( $p$-coumaric acid, caffeic acid and chlorogenic acid) and rutin, by Sigma (St. Louis, MO, USA); procyanidin B2 and quercetin glycosides (hyperin, isoquercitrin, avicularin and quercitrin) by Extrasynthèse (Genay, France), and reynoutrin, by Apin Chemicals (Abingdon, UK). DMEM and foetal bovine serum were purchased from Sigma (St. Louis, MO, USA).

\subsection{Methods}

\subsubsection{Extractions}

Apple pomace ( $10 \mathrm{~g}$ ) was extracted with $100 \mathrm{~mL}$ of $70 \%$ acetone (acetonic extract, $\mathrm{AE}$ ) or $80 \%$ methanol (methanolic extract, ME) in darkness, by magnetic stirring at $20^{\circ} \mathrm{C}$. The extracts were filtered through no. 1 Whatman paper on a vacuum-aided Buchner funnel and concentrated to dryness by rotary evaporation at $30^{\circ} \mathrm{C}$, under reduced pressure. The solid residue was dissolved in distilled water and lyophilised. The total extraction process was done in duplicate.

\subsubsection{Determination of total phenolic content}

The contents of total phenolics in samples were analysed by the Folin-Ciocalteu colorimetric method. The appropriate extracts dilutions were oxidised with Folin-Ciocalteu reagent and the reaction was stopped with sodium carbonate. After $30 \mathrm{~min}$ incubation, the absorbance of the resulting blue product was measured at $750 \mathrm{~nm}$ with a Perkin-Elmer Lambda 35 spectrophotometer. Gallic acid was used as standard.

\subsubsection{Liquid chromatographic analysis of phenolic compounds}

HPLC analysis was performed according to the method validated by our group (Suárez, Palacios, Fraga, \& Rodríguez, 2005). We used a Waters system equipped with a 717 automatic injector, provided with a column oven, two pumps (model 510), a diode array detector (model 2996) and Millennium software v.3.1 data module. Separation of polyphenols was carried out on a reversed-phase Nucleosil $120 \mathrm{C}_{18}(250 \times 4.6 \mathrm{~mm}$ ID, $3 \mu \mathrm{m})$ column from Teknokroma (Barcelona, Spain) thermostated at $25^{\circ} \mathrm{C}$, and a flow rate of $0.8 \mathrm{~mL} / \mathrm{min}$ was used. The elution solvents were aqueous $2 \%$ acetic acid (solvent $\mathrm{A}$ ) and $100 \%$ methanol (solvent $\mathrm{B}$ ). The samples were eluted according to the following gradient: a linear step from $0 \%$ to $45 \%$ of solvent B in $55 \mathrm{~min}$ and a final isocratic step of $20 \mathrm{~min}$. Fifty microlitre of each organic extract were injected into the HPLC after filtration through a $0.22 \mu \mathrm{m}$ PVDF membrane. Quantitation was performed at $313 \mathrm{~nm}$ for the hydroxycinnamic acids, $355 \mathrm{~nm}$ for the flavonol glycosides and $280 \mathrm{~nm}$ for the rest of phenolic compounds. Quantitation was performed according to the external standard method. For compounds lacking of standards, or those whose standard amount at our disposal was too small, the quantification was achieved from similar compounds: thus, phloretin-2'-xyloglucoside and the unknown dihydrochalcones were quantified as phloridzin and flavonol glycosides as quercitrin.

\subsubsection{Radical-scavenging activity (DPPH)}

The free radical-scavenging activity of apple pomace extracts was measured using the DPPH (1,1-diphenyl-2-picrylhydrazyl) method. A $40 \mu \mathrm{L}$ aliquot of diluted sample was added to $1.460 \mathrm{~mL}$ of DPPH solution in methanol $\left(1.0 \times 10^{-4} \mathrm{M}\right)$ and the reaction mixture was kept in the dark for $240 \mathrm{~min}$. The absorption was read at $515 \mathrm{~nm}$ relative to control (100\%) and the scavenging effect percentage was expressed as $I=\left(1-\left(A_{515}\right.\right.$ of sample $/ A_{515}$ of control) $\times 100$ ). The antioxidant capacity was expressed as ascorbic acid equivalents ( $\mathrm{g}$ ascorbic acid/kg dry matter), calculated from the following equation: $I=0.2376 C-0.3392\left(R^{2}=0.997\right)$.

\subsubsection{Ferric reducing-antioxidant power (FRAP)}

FRAP assay measures the reduction of ferric iron to the ferrous form in the presence of the antioxidant components. The working FRAP reagent was prepared freshly every day by mixing $2.5 \mathrm{~mL}$ of TPTZ (10 mM in $40 \mathrm{mM}$ hydrochloric acid), $2.5 \mathrm{~mL}$ of ferric chloride (20 mM) and $25 \mathrm{~mL}$ of sodium acetate buffer ( $300 \mathrm{mM}, \mathrm{pH} 3.6)$. The FRAP assay was carried out at $37^{\circ} \mathrm{C}$, in $1-\mathrm{cm}$ disposable plastic cells. Nine hundred microlitre of the FRAP reagent were mixed with $90 \mu \mathrm{L}$ of water and $30 \mu \mathrm{L}$ of apple pomace extract (diluted 1:25 with methanol). After $120 \mathrm{~min}$, the absorbance at $595 \mathrm{~nm}$ was measured. The antioxidant capacity of the apple pomaces were expressed as $\mathrm{g}$ ascorbic acid/kg dry matter.

\subsubsection{Cytotoxicity assay}

Vero cells were seeded into 96 -well plates at a density of $2 \times 10^{4}$ cells/well, and incubated at $37^{\circ} \mathrm{C}$ in $5 \% \mathrm{CO}_{2}$ atmosphere during 48-72 h until confluent monolayers were formed. Increasing concentrations of the test extracts $(500-12,000 \mu \mathrm{g} / \mathrm{mL})$ were added, with a replicate number of six wells per concentration. Cells were incubated in these conditions with the test extracts during $72 \mathrm{~h}$. After this incubation period, $10 \mu \mathrm{L}$ of a PBS-solution containing $5 \mathrm{mg} / \mathrm{mL}$ of 3-(4,5-dimethylthiazol-2-yl)-2,5-diphenyl tetrazolium bromide (MTT) were added into each well and the plates were incubated for another $4 \mathrm{~h}$. Plates were decanted by gently inversion and the produced solid precipitate was dissolved with 100 $\mu \mathrm{L} /$ well of a solution containing $1 \mathrm{~N} \mathrm{HCl}$ in anhydrous 2-propanol and the absorbance at $570 \mathrm{~nm}$ was determined using a MicroQuant spectrophotometer with a reference wavelength of $620 \mathrm{~nm}$. The cell viability percentage was calculated as the ratio between the mean absorbance of treated with respect to that of untreated wells (Mosmann, 1983).

\subsubsection{Antiviral assay}

About 96-well plates with confluent cell monolayers were preincubated for $1 \mathrm{~h}$ with increasing non-cytotoxic concentrations of the extracts in the range of $50-1000 \mu \mathrm{g} / \mathrm{mL}$. Six wells were used for each concentration. Afterwards, $10 \mu \mathrm{L}$ of a virus dilution containing $100 \mathrm{TCID}_{50}$ of HSV-1 or HSV-2 were added into each well. Plates were incubated at $37^{\circ} \mathrm{C}$ in $5 \% \mathrm{CO}_{2}$ atmosphere and microscopically observed daily for CPE. When at least one CPE focus was observed in every virus control well, the percentage of wells with CPE among treated wells was determined for each treatment concentration (del Barrio \& Parra, 2000). Acyclovir (ACV) at concentrations varying from 0.5 to $8 \mu \mathrm{g} / \mathrm{mL}$ served as positive controls.

\subsubsection{Statistical analysis}

Statistical analyses were performed with the SPSS software package. Differences among extracts were determined using Student $t$-tests. Cytotoxic mean concentration $\left(\mathrm{CC}_{50}\right)$ and antiviral effective mean concentration $\left(\mathrm{EC}_{50}\right)$ values were obtained by 
regression analysis of the dose-response curves generated from data.

\section{Results and discussion}

\subsection{Phenolic profiles and antioxidant activity}

Methanolic (ME) and acetonic (AE) extracts from apple pomace were evaluated to compare their total phenolic content, phenolic profiles and antioxidant capacity. An aliquot of each lyophilised extract $(30 \mathrm{mg})$ was dissolved in methanol $(10 \mathrm{~mL})$. All data are presented as mean value of three replications and its standard deviation (SD).

Table 1 summarises the concentrations of phenolic compounds, the radical-scavenging activity and reducing power of apple pomace extracts.

In this industrial pomace, a total of 12 phenolic compounds (three phenolic acids and nine flavonoids) were identified by comparison of their retention times and UV-Vis spectra with those of standards. Furthermore, two other unknown compounds exhibit-

Table 1

Phenolic composition and antioxidant activity of apple pomace.

\begin{tabular}{|c|c|c|c|c|}
\hline & $\mathrm{AE}$ & SD & ME & SD \\
\hline \multicolumn{5}{|l|}{ Benzoic acids (1) } \\
\hline Protocatechuic acid & 134.33 & 5.32 & 118.19 & 3.46 \\
\hline \multicolumn{5}{|l|}{ Hydroxycinnamic acids (1) } \\
\hline Chlorogenic acid & 166.12 & 0.05 & 170.56 & 4.74 \\
\hline Caffeic acid & 22.27 & 0.07 & 19.68 & 0.72 \\
\hline \multicolumn{5}{|l|}{ Procyanidins and flavan-3-ols (1) } \\
\hline $\mathrm{B} 2^{*}$ & 74.87 & 0.95 & 65.67 & 1.09 \\
\hline Epicatechin & 88.45 & 1.48 & 88.21 & 0.87 \\
\hline \multicolumn{5}{|l|}{ Dihydrochalcones (1) } \\
\hline Unknown dihydrochalcone $(\mathrm{a})^{*}$ & 13.11 & 0.35 & 3.20 & 0.00 \\
\hline Unknown dihydrochalcone (b) & 88.09 & 0.01 & 9.51 & 0.06 \\
\hline Phloretin-2'-xyloglucoside & 170.72 & 0.11 & 170.04 & 0.62 \\
\hline Phoridzin $^{*}$ & 380.05 & 2.72 & 362.28 & 1.83 \\
\hline \multicolumn{5}{|l|}{ Flavonols (1) } \\
\hline Hyperin ${ }^{*}$ & 253.71 & 0.59 & 213.01 & 0.86 \\
\hline 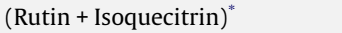 & 122.28 & 0.10 & 103.26 & 1.56 \\
\hline Reynoutrin $^{*}$ & 73.97 & 0.89 & 59.51 & 0.26 \\
\hline Avicularin ${ }^{*}$ & 185.10 & 1.66 & 146.46 & 0.18 \\
\hline Quercitrin ${ }^{*}$ & 131.78 & 2.69 & 105.58 & 0.08 \\
\hline Total phenols $(2)^{*}$ & 6.48 & 0.29 & 3.63 & 0.02 \\
\hline $\mathrm{DPPH}(3)^{*}$ & 9.75 & 1.15 & 6.66 & 0.76 \\
\hline $\operatorname{FRAP}(3)^{*}$ & 10.87 & 0.26 & 7.73 & 0.26 \\
\hline
\end{tabular}

(1) $\mathrm{mg} / \mathrm{kg}$ dry weight pomace, (2) g gallic acid/kg dry weight pomace, and (3) g ascorbic acid/kg dry weight pomace.

$\mathrm{AE}$, acetonic extract; ME, methanolic extract.

Significant differences between extracts $(p<0.05)$.

A

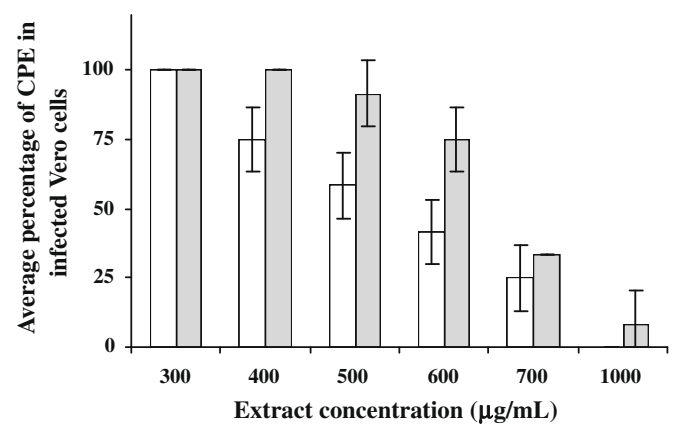

ing spectral characteristics similar to phloridzin $\left(\lambda_{\max }=284.0 \mathrm{~nm}\right)$ were determined. With regard to the phloretin derivatives, the 3hydroxyphloretin 2'-xyloglycoside and 2'-glucoside had been described in apple products (Lu \& Foo, 1997; Tsao, Yang, Young, \& Zhu, 2003). The predominant phenolic families were quercetin glycosides followed by dihydrochalcones. Five quercetin glycosides were detected; two flavonols, hyperin and avicularin, represented more than $50 \%$ of total flavonols in pomace, hyperin being the predominant. Phloridzin and phloretin-2'-xyloglucoside were the major dihydrochalcones quantified with content values around $20 \%$ and $10 \%$ of the total phenolic compounds, respectively. Minor compounds found in apple pomace were phenolic acids, epicatechin and procyanidin B2. The range of concentrations of phenolic compounds determined was consistent with previous reports in literature (Price, Prossert, Richetin, \& Rhodes, 1999; Schieber, Keller, \& Carle, 2001; Van Der Sluis, Dekker, Skrede, \& Jongen, 2002).

Aqueous acetone showed to be slightly more efficient than aqueous methanol for phenolic compounds extraction, except for chlorogenic acid. This result agrees with previous reports (Heinonen, Meyer, \& Frankel, 1998; Kahkonen, Hopia, \& Heinonen, 2001).

It was found that both extracts showed remarkable antioxidant activities, but the acetonic extract exerted 1.4 times more radicalscavenging activity and reducing-antioxidant power than the methanolic one.

Significant differences were found among extracts for total phenols (Folin-Ciocalteu method), procyanidin B2, flavonol glycosides, three different dihydrochalcones and antioxidant activities (Table 1).

\subsection{Cytotoxic effects and antiviral activity of apple pomace extracts}

In order to assess the cytotoxic effects of apple pomace a colorimetric MTT assay was performed after incubating cell cultures with increasing concentrations of the extracts, as previously described (Mosmann, 1983). The $\mathrm{CC}_{50}$ values obtained for these extracts on Vero cells were $5494.9 \pm 292.4 \mu \mathrm{g} / \mathrm{mL}$ and $7281.8 \pm$ $509.5 \mu \mathrm{g} / \mathrm{mL}$ for AE and ME extracts, respectively. These values correlated well with morphological changes recorded during microscopic examination of treated cultures. These changes consisted of cell rounding, appearance of cytoplasmic inclusions and the loss of monolayer confluence, and became evident with treatment concentration over $7000 \mu \mathrm{g} / \mathrm{mL}$. At $1200 \mu \mathrm{g} / \mathrm{mL}$, the highest concentration used in antiviral assays, the mean cell viability was close to $90 \%$ and $80 \%$ for $\mathrm{AE}$ and $\mathrm{ME}$ extracts, respectively (data not shown).

As part of an ongoing study on the properties of apple pomace, we demonstrated its efficacy in reducing viral replication levels, when assessed against HSV-1 and HSV-2, two enveloped viruses considered as human pathogens of major clinical interest, since

B

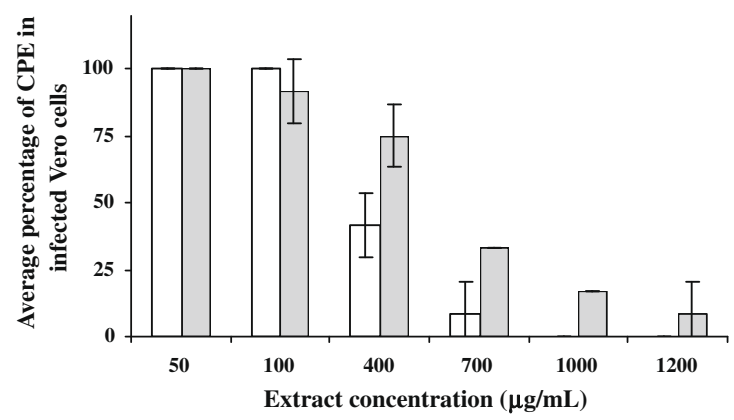

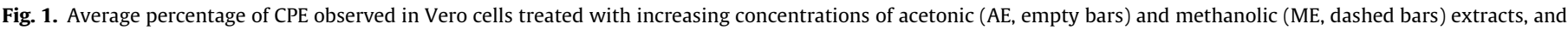
infected with HSV-1 (A) or HSV-2 (B) clinical isolates. Data are presented as mean of three independent experiments and its standard deviation. 
Table 2

Antiviral activity of apple pomace extracts. Data are presented as mean of three independent experiments and its standard deviation.

\begin{tabular}{lllllll}
\hline Extracts & $\mathrm{CC}_{50}{ }^{\mathrm{a}}\left(\mu \mathrm{g}^{*} / \mathrm{mL}\right)$ & $\mathrm{HSV}-1$ & & $\mathrm{HSV}-2$ & \\
\cline { 3 - 4 } & & $\mathrm{CE}_{50}{ }^{\mathrm{b}}\left(\mu \mathrm{g}^{*} / \mathrm{mL}\right)$ & $\mathrm{SI}$ & & $\mathrm{CE}_{50}\left(\mu \mathrm{g}^{*} / \mathrm{mL}\right)$ & $\mathrm{SI}$ \\
\hline $\mathrm{AE}$ & $5494.9 \pm 292.4$ & $576.7 \pm 17.2$ & 9.5 & & $450.7 \pm 40.8$ & 12.2 \\
$\mathrm{ME}$ & $7281.8 \pm 509.5$ & $710.9 \pm 1.6$ & 10.2 & & $629.6 \pm 50.7$ & 11.6 \\
$\mathrm{ACV}^{\mathrm{c}}$ & $>100$ & 2.8 & $>35.7$ & & 5.1 & $>19.6$ \\
\hline
\end{tabular}

a Concentration reducing cell viability by $50 \%$.

b Concentration reducing virus-induced CPE by $50 \%$.

c Data from an individual experiment.

$\mu \mathrm{g}$ of lyophilised pomace extract.

they are associated with high morbidity and globally spread human diseases.

Morphological alterations of Vero cells induced by the replication of HSV-1 and HSV-2 were completely prevented when $1000 \mu \mathrm{g} / \mathrm{mL}$ of AE were present in infected cell cultures. Likewise, a concentration of $1200 \mu \mathrm{g} / \mathrm{mL}$ of ME was able to decrease the percentage of CPE by more than 90\% (Fig. 1A and B). For each extract and virus species a selectivity index (SI) was calculated by dividing the $\mathrm{CC}_{50}$ by the corresponding $\mathrm{EC}_{50}$ value (Table 2 ).

The inhibition of virus replication is achieved within extracts concentration ranges which were at least nine orders lower than those of cytotoxic concentrations.

Both, HSV-1 and HSV-2 viruses used in this study were considered $A C V$-resistant isolates, since $\mathrm{EC}_{50}$ values found for this nucleoside analogue were greater than $2 \mu \mathrm{g} / \mathrm{mL}$, as has previously been reported (Stranska, van Loon, Polman, \& Schuurman, 2002).

The antiherpetic properties of apples pomace must be probably due to the presence of flavonoids which are known to inhibit theses viruses (de Bruyne et al., 1999; Khan, Ather, Thompson, \& Gambari, 2005).

Taken together, the beneficial properties of these apple residues outlined in this work aim at highlighting the feasibility of its use with medicinal purposes, as a dietary supplement, or included in topical formulations to treat the herpetic skin symptomatic lesions. At present, our group is analysing different types of apple pomaces (single-cultivar and industrial) in order to compare their antioxidant and antiviral activities.

\section{Acknowledgements}

This work was partially supported by the Regional Government of the Principality of Asturias and the Town Hall of Villaviciosa. Antiviral study was performed within the framework of a collaboration agreement between the Universities of Oviedo (Asturias, Spain) and La Habana (Cuba), financed by the Town Hall of Gijón (Asturias, Spain).

\section{References}

Block, G., Patterson, B., \& Subar, A. (1992). Fruit, vegetables, and cancer prevention: A review of the epidemiological evidence. Nutrition and Cancer, 18(1), 1-29.
Boyer, J., Brown, D., \& Liu, R. H. (2004). Uptake of quercetin and quercetin 3glucoside from whole onion and apple peel extracts by Caco-2 cell monolayers. Journal of Agricultural and Food Chemistry, 52(23), 7172-7179.

Ćetković, G., Čanadanović-Brunet, J., Djilas, S., Savatović, S., Mandić, A., \& Tumbas, V. (2008). Assessment of polyphenolic content and in vitro antiradical characteristics of apple pomace. Food Chemistry, 109(2), 340-347.

Cos, P., Berghe, V. D., Bruyne, T. D., \& Vlietinck, A. J. (2003). Plant substances as antiviral agents: An update (1997-2001). Current Organic Chemistry, 7(12) 1163-1180.

de Bruyne, T., Pieters, L., Witvrouw, M., De Clercq, E., Vanden Berghe, D., \& Vlietinck A. J. (1999). Biological evaluation of proanthocyanidin dimers and related polyphenols. Journal of Natural Products, 62(7), 954-958.

del Barrio, G., \& Parra, F. (2000). Evaluation of the antiviral activity of an aqueous extract from Phyllanthus orbicularis. Journal of Ethnopharmacology, 72(1-2) 317-322.

Foo, L. Y., \& Lu, Y. (1999). Isolation and identification of procyanidins in apple pomace. Food Chemistry, 64(4), 511-518.

Goncalves, J. L., Leitao, S. G., Monache, F. D., Miranda, M. M., Santos, M. G., Romanos, M. T., et al. (2001). In vitro antiviral effect of flavonoid-rich extracts of Vitex polygama (Verbenaceae) against acyclovir-resistant herpes simplex virus type 1 . Phytomedicine, 8(6), 477-480.

Heinonen, I. M., Meyer, A. S., \& Frankel, E. N. (1998). Antioxidant activity of berry phenolics on human low-density lipoprotein and liposome oxidation. Journal of Agricultural and Food Chemistry, 46(10), 4107-4112.

Hertog, M. G., Feskens, E. J., Hollman, P. C., Katan, M. B., \& Kromhout, D. (1993) Dietary antioxidant flavonoids and risk of coronary heart disease: The zutphen elderly study. Lancet, 342(8878), 1007-1011.

Kahkonen, M. P., Hopia, A. I., \& Heinonen, M. (2001). Berry phenolics and their antioxidant activity. Journal of Agricultural and Food Chemistry, 49(8) 4076-4082.

Khan, M. T., Ather, A., Thompson, K. D., \& Gambari, R. (2005). Extracts and molecules from medicinal plants against herpes simplex viruses. Antiviral Research, 67(2), 107-119.

Leontowicz, H., Gorinstein, S., Lojek, A., Leontowicz, M., Ci, Z. M., Soliva-Fortuny, R. et al. (2002). Comparative content of some bioactive compounds in apples, peaches and pears and their influence on lipids and antioxidant capacity in rats. Journal of Nutritional Biochemistry, 13(10), 603-610.

Lu, Y., \& Foo, L. Y. (1997). Identification and quantification of major polyphenols in apple pomace. Food Chemistry, 59(2), 187-194.

Lu, Y., \& Foo, L. Y. (2000). Antioxidant and radical scavenging activities of polyphenols from apple pomace and vegetables. Food Chemistry, 68(1), 81-85.

Mosmann, T. (1983). Rapid colorimetric assay for cellular growth and survival: Application to proliferation and cytotoxicity assays. Journal of Immunology Methods, 65(1-2), 55-63.

Price, K. R., Prossert, T., Richetin, A. M. F., \& Rhodes, M. J. C. (1999). A comparison of the flavonol content and composition in dessert, cooking and cider-making apples; distribution within the fruit and effect of juicing. Food Chemistry, 66(4), 489-494.

Reed, L. J., \& Muench, H. (1938). A simple method of estimating fifty per cent endpoints. American Journal of Hygiene, 27, 493-497.

Schieber, A., Keller, P. \& Carle, R. (2001). Determination of phenolic acids and flavonoids of apple and pear by high-performance liquid chromatography. Journal of Chromatograph A, 910(2), 265-273.

Stranska, R., van Loon, A. M., Polman, M., \& Schuurman, R. (2002). Application of real-time PCR for determination of antiviral drug susceptibility of herpes simplex virus. Antimicrobial Agents and Chemotherapy, 46(9), 2943-2947.

Suárez, B., Palacios, N., Fraga, N., \& Rodríguez, R. (2005). Liquid chromatographic method for quantifying polyphenols in ciders by direct injection. Journal of Chromatography A, 1066(1-2), 105-110.

Tsao, R., Yang, R., Young, J. C., \& Zhu, H. (2003). Polyphenolic profiles in eight apple cultivars using high-performance liquid chromatography (HPLC). Journal of Agricultural and Food Chemistry, 51(21), 6347-6353.

Van Der Sluis, A. A., Dekker, M., Skrede, G., \& Jongen, W. M. (2002). Activity and concentration of polyphenolic antioxidants in apple juice. 1. Effect of existing production methods. Journal of Agricultural and Food Chemistry, 50(25), 7211-7219.

Whitley, R. J., Kimberlin, D. W., \& Roizman, B. (1998). Herpes simplex viruses. Clinical Infectious Diseases, 26(3), 541-553. 